\title{
Experimental Investigation on Micro Deep Drawing of Stainless Steel Foils with Different Microstructural Characteristics
}

\author{
Jingwei Zhao ${ }^{1,2,3}$, Tao Wang ${ }^{1,2,3^{*}}$, Fanghui Jia ${ }^{4,5}$, Zhou Li ${ }^{4,5}$, Cunlong Zhou ${ }^{6}$, Qingxue Huang ${ }^{1,2,3}$ and \\ Zhengyi Jiang $4,5,6^{*}$
}

\begin{abstract}
In the present work, austenitic stainless steel (ASS) 304 foils with a thickness of $50 \mu \mathrm{m}$ were first annealed at temperatures ranging from 700 to $1100{ }^{\circ} \mathrm{C}$ for $1 \mathrm{~h}$ to obtain different microstructural characteristics. Then the effects of microstructural characteristics on the formability of ASS 304 foils and the quality of drawn cups using micro deep drawing (MDD) were studied, and the mechanism involved was discussed. The results show that the as-received ASS 304 foil has a poor formability and cannot be used to form a cup using MDD. Serious wrinkling problem occurs on the drawn cup, and the height profile distribution on the mouth and the symmetry of the drawn cup is quite nonuniform when the annealing temperature is $700{ }^{\circ} \mathrm{C}$. At annealing temperatures of 900 and $950{ }^{\circ} \mathrm{C}$, the drawn cups are both characterized with very few wrinkles, and the distribution of height profile, symmetry and mouth thickness are uniform on the mouths of the drawn cups. The wrinkling becomes increasingly significant with a further increase of annealing temperature from 950 to $1100{ }^{\circ} \mathrm{C}$. The optimal annealing temperatures obtained in this study are 900 and $950{ }^{\circ} \mathrm{C}$ for reducing the generation of wrinkling, and therefore improving the quality of drawn cups. With nonoptimized microstructure, the distribution of the compressive stress in the circumferential direction of the drawn foils becomes inhomogeneous, which is thought to be the cause of the occurrence of localized deformation till wrinkling during MDD.
\end{abstract}

Keywords: Microforming, Micro deep drawing, Stainless steel foils, Wrinkling, Annealing, Microstructure

\section{Introduction}

Driven by ongoing miniaturization in diverse areas including medical devices, precision equipment, communication devices, micro-electromechanical systems and micro fluidics systems, the demands for micro metallic parts have been tremendously increased [1-4]. As a fundamental microforming process, micro deep drawing (MDD) has extensive applications in the forming of hollow, thin walled and cup-like micro metallic parts.

\footnotetext{
*Correspondence: tyutwt@163.com; jiang@uow.edu.au

${ }^{1}$ College of Mechanical and Vehicle Engineering, Taiyuan University of Technology, Taiyuan 030024, China

${ }^{4}$ TYUT-UOW Joint Research Center, University of Wollongong,

Wollongong, NSW 2522, Australia

Full list of author information is available at the end of the article
}

However, due to the common problem of size effects existed in the forming of metals in microscale, research on MDD becomes more comprehensive as compared to those on the conventional deep drawing. As a result, a large number of studies have been conducted to identify the size effects in MDD of metals with the purpose of manufacturing high quality micro parts and promoting the development of MDD technology [5-7].

Austenitic stainless steels (ASSs) possess austenite as its primary crystalline structure, and have excellent corrosion resistance while maintaining high mechanical strength [8]. Micro cups produced with ASSs are extensively used in medical and electronic devices, and the research on MDD of ASSs has been increasing tremendously for years. Chen et al. [9] conducted experimental 
and analytical studies on the MDD of ASS 304 foils annealed at 900, 950, 1000 and $1050{ }^{\circ} \mathrm{C}$, and found that the limit drawing ratio (LDR) of ASS 304 foils increased with the increase of annealing temperature when the thickness of the foils was kept the same. Their research results showed that size effects were noticeable and significant when the thickness of the foils was equal to or less than $100 \mu \mathrm{m}$, and foil thickness, grain size and ratio of foil thickness $(T)$ to grain size $(D)$ affected significantly the value of LDR of ASS 304 foils. Ma et al. [10] established a numerical model to investigate the MDD with radial pressure, and found that appropriate radial pressure and gap distance could improve the LDR of drawn ASS 304 circular cups by reducing the friction resistance. Huang et al. [11] investigated the MDD with assistance of ultrasonic vibration. The results showed that the LDR of $50 \mu \mathrm{m}$ thick ASS 304 foil could be increased from 1.67 to 1.83 with the application of an oscillation amplitude of $2.1 \mu \mathrm{m}$. Sato et al. $[12,13]$ developed a micro hydro deep drawing apparatus and applied it to the MDD of ASS 304 foils. They found that the tribological behavior of ASS 304 foils in MDD could be improved, and the wrinkling occurred at the edge of drawn cups could be suppressed through appropriate control of hydraulic pressure. Luo et al. $[14,15]$ studied the effects of hydraulic pressure on the surface quality of ASS 304 drawn cups in terms of wrinkling and earing, and pointed out that an increase in hydraulic pressure would contribute to the solving of wrinkling and earing problems of the drawn cups.

For obtaining different grain sizes, Luo et al. [16-18] carried out annealing treatment of ASS 304 foils at 975, 1050 and $1100{ }^{\circ} \mathrm{C}$, and studied the effects of grain size on the surface quality of drawn cups numerically and experimentally. They found that wrinkling phenomenon became significant with the increase of grain size, and ASS 304 foil annealed at $975{ }^{\circ} \mathrm{C}$ could be used to fabricate high quality cups by MDD. Chang and Chen [19] studied the grain size effects on the MDD of ASS 304 square cups. Their research results indicated that grain size affected the surface roughness of the drawn cups, and the smaller the grain size the smoother the surface texture would be. Lee et al. [20] pointed out that ASS 304 foils should contain at least 10 grains throughout the thickness $(T / D>10)$ for improved formability and steady deep drawing behavior in MDD. In order to obtain a large ratio of drawn ASS 304 cup height to cup outer diameter, Gau et al. [21] proposed a combined process consisting of one MDD and two ironing stages. They recommended that ASS 304 foil annealed at $1050{ }^{\circ} \mathrm{C}$ was optimal for forming high quality cup in terms of cup height and geometry control with the least cost.

The above literature reviews indicate that the research into the deformation behavior of ASSs, especially ASS
304, during MDD has been extensively conducted. However, it is still short of investigation on the MDD of ASS 304 foils with different microstructural characteristics, even though the methods for improving the quality of drawn ASS 304 cups have been proposed by some researchers. The microstructure of an ASS 304 foil determines its mechanical response, and affects the MDD behavior and finally the quality of the drawn parts. It is therefore essential to build the relationship between the microstructural characteristics and the quality of drawn parts so that control strategies can be obtained for forming high quality micro ASS 304 cups using MDD. The objective of the current work is to investigate the MDD of ASS 304 foils undertaking annealing treatment at temperatures ranging from 700 to $1100{ }^{\circ} \mathrm{C}$. Such a wide range of annealing temperature enables the generation of different microstructural characteristics. The effects of microstructure on the formability of ASS 304 foils and the quality of drawn cups will be investigated and discussed, and the optimal annealing temperatures for forming high quality drawn cups will be proposed. The current work will contribute to the understanding of the effects of microstructure on the MDD of ASS 304 foils and the forming of high quality drawn cups.

\section{Experimentation}

\subsection{Material}

Cold-rolled ASS 304 foils, which are widely used in the manufacturing of micro device components, with a thickness of $50 \pm 2 \mu \mathrm{m}$ were selected as the research material in the current work. The microstructure of the as-received ASS 304 foils is presented in Figure 1, and the chemical compositions are listed in Table 1. The asreceived ASS 304 foils were annealed at the temperatures of $700,850,900,950,1000$ and $1100{ }^{\circ} \mathrm{C}$ for $1 \mathrm{~h}$ in an argon gas protection atmosphere for obtaining different microstructural characteristics. Once the temperature reached the designated value, the temperature was maintained for $1 \mathrm{~h}$ and then the furnace was turned

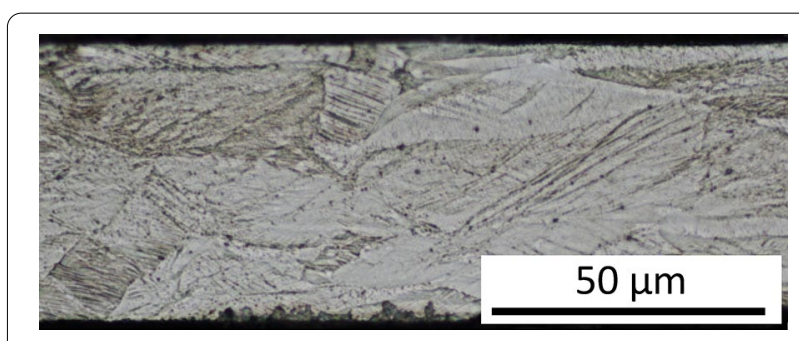

Figure 1 Microstructure of the as-received ASS 304 foils 
Table 1 Chemical compositions of the studied ASS 304 (wt\%)

\begin{tabular}{lllllll}
\hline$C$ & Si & Mn & Cr & Ni & $P$ & S \\
\hline 0.05 & 0.60 & 0.96 & 18.20 & 8.05 & 0.035 & 0.004 \\
\hline
\end{tabular}

off till cooled to room temperature. The specimens annealed at 700, 850, 900, 950, 1000 and $1100{ }^{\circ} \mathrm{C}$ are named as A700, A850, A900, A950, A1000 and A1100, respectively.

\subsection{Tensile Tests}

Tensile specimens were prepared according to the ASTM E8/E8M-11 standard (gauge length $30 \mathrm{~mm}$, and gauge width $6 \mathrm{~mm}$ ) [22]. Tensile tests were performed on an INSTRON 5566 tensile testing machine at room temperature with the stroke speed of $1 \mathrm{~mm} / \mathrm{min}$. Four specimens were used under each condition in the tensile tests.

\subsection{Micro Deep Drawing Tests}

A Desk-top servo press machine DT-3AW was used to conduct the MDD tests, as shown in Figure 2a, and the key parameters of MDD tools are presented in Figure 2b. The MDD toolset was driven by the press machine which was controlled by the PLC modulus in the control and data logging box. The press machine has a capacity of the maximum force of $30 \mathrm{kN}$ and the maximum displacement of $40 \mathrm{~mm}$. The surfaces of all the foils were slightly polished using a soft eraser and then cleaned by alcohol to remove surface contamination before MDD tests, by which the foils have an identical surface roughness of $0.318 \mu \mathrm{m}$ in $R_{a}$. Firstly, the blanking die and the blanking holder moved downwards at a speed of $0.1 \mathrm{~mm} / \mathrm{s}$ and the die stayed still as a blanking punch. Under this process, a raw blank for the following drawing process was cut at the first half stroke. Then, the punch moved down continuously and contacted with the blank, whereas the die stayed still. Finally, a micro circular cup was drawn by the punch at the end of the second half stroke. Due to this design of the MDD toolset, the press machine performing one stroke can fulfil the blanking and the MDD processes subsequently. During the drawing process, the drawing force was recorded and exported to a computer for further analysis. The data acquisition system was developed based on data conversion. After drawing process, the drawn cups were removed from the mouth of the die. Then, the cups were cleaned by ultrasonic bath with alcohol for $1 \mathrm{~min}$ and air-dried before microscopic observation.

\subsection{Characterization Methodology}

Metallographic specimens were etched with a solution of " $15 \mathrm{~mL} \mathrm{HCl}+10 \mathrm{~mL}$ acetic acid $+5 \mathrm{~mL} \mathrm{HNO}_{3}+2$ drops glycerol" for $3 \mathrm{~s}$ to reveal the microstructure, and then were observed by a Nikon Eclipse LV100NDA optical microscope (OM). A digital microscope of VHX$1000 \mathrm{X}$ was used to observe the $3 \mathrm{D}$ profile of the drawn cups, which were further analyzed by a high-resolution VK-X100 laser scanning microscope for obtaining more detailed information. Under the laser scanning microscope, the cups were colored based on the variations of the cup heights.

\section{Results and Discussion}

\subsection{Microstructure}

The OM microstructure of the annealed ASS 304 foils in the thickness direction is shown in Figure $3 \mathrm{a}-\mathrm{f}$, which correspond to the specimens A700, A850, A900, A950, A1000 and A1100, respectively. It can be seen from Figure $3 \mathrm{a}$ that the grains in the specimen A700 exhibit a deformed characteristic, which indicates no obvious recrystallization has occurred during annealing

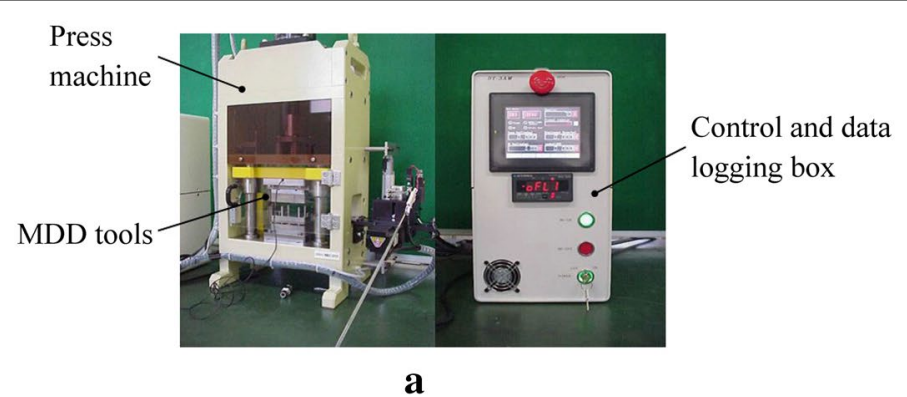

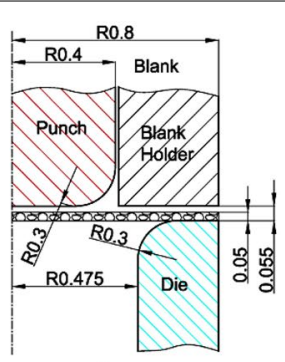

b

Figure 2 a Desk-top servo press machine DT-3AW, b key parameters of MDD tools (unit: $\mathrm{mm}$ ) 


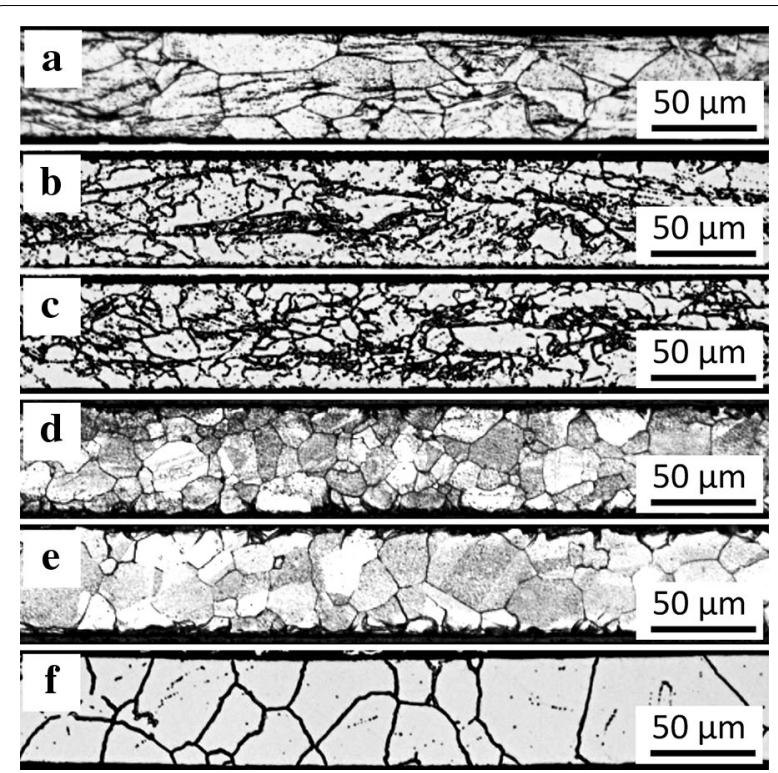

Figure 3 Microstructure of the annealed specimens: a A700, b A850, c A900, d A950, e A1000, f A1100

at $700{ }^{\circ} \mathrm{C}$. At the temperature of $850{ }^{\circ} \mathrm{C}$ (Figure 3b), the elongated grains are being broken up, and a number of recrystallized grains are found to grow up by consuming the surrounding heavily deformed region. When the temperature is increased to $900{ }^{\circ} \mathrm{C}$ (Figure 3c), the newly recrystallized grains become more visible but deformed characteristic is still observable in some regions along the longitudinal direction, indicating that recrystallization process has not yet completed at this temperature. With a further increase of temperature to $950{ }^{\circ} \mathrm{C}$ (Figure 3d), the microstructure consists of fully recrystallized grains. The grains become coarser and the size distribution of grains becomes more uniform when the temperature is increased from 950 to $1000{ }^{\circ} \mathrm{C}$ (Figure 3e). At the highest annealing temperature of $1100{ }^{\circ} \mathrm{C}$, the microstructure is composed of very coarse grains (Figure 3f), indicating that significant growing up process of recrystallized grains has occurred at this temperature [23].

The occurrence of recrystallization of ASS 304 depends on a number of factors, including heat treatment performed before cold working, the degree, mode and strain rate at cold working, and the heating rate and holding time at annealing temperature [24]. Recrystallization occurs at the deformation bands and in the vicinity of grain boundaries [25]. All the variables that increase the stored energy due to deformation lead to a decrease in recrystallization temperature. Sun et al. [26] reported that the start temperature for recrystallization of ASS 304 was over $850{ }^{\circ} \mathrm{C}$, while Zheng et al. [27] found that the recrystallization of ASS 304 started at $650{ }^{\circ} \mathrm{C}$. Therefore,

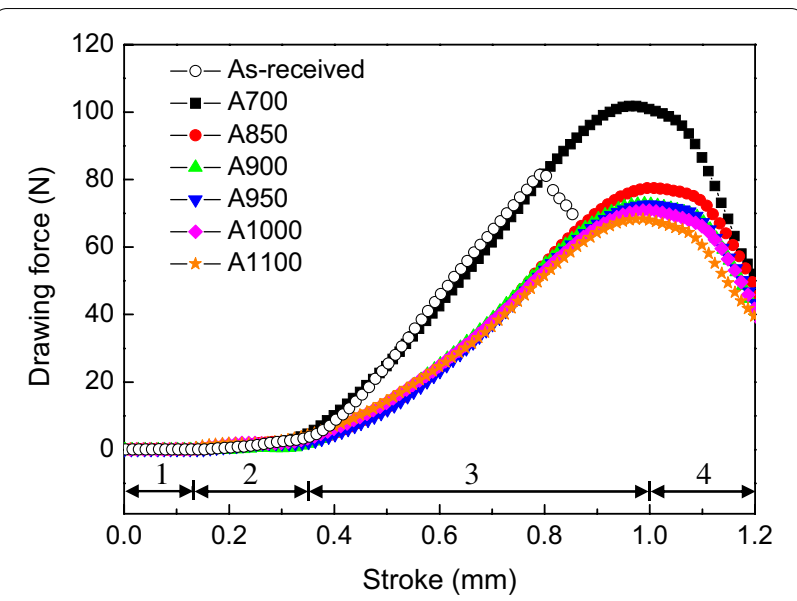

Figure 4 Variations of drawing force with stroke during MDD

it is hard to specify a recrystallization temperature for the steel grade of ASS 304 due to a large number of variables and the complexity of recrystallization phenomena involved. In the current work, linear intercept method according to the ASTM E112-13 standard [28] was used to determine the average grain size of the ASS 304 foils in their thickness directions. Six random OM images, along the longitudinal direction on the thickness section, without bias were used for grain size determination, and for each OM image five blindly drawn lines were counted. Then the grain size was averaged from the total 30 measurements. The calculated average grain sizes for the specimens A950, A1000 and A1100 are $12 \mu \mathrm{m}, 20 \mu \mathrm{m}$ and $46 \mu \mathrm{m}$, respectively.

\subsection{Drawing Force}

The drawing forces obtained from six MDD tests for each specimen were recorded, and the average values were used for analysis. Figure 4 shows the variations of drawing force with stroke during MDD for the as-received and annealed specimens. The drawing force of the asreceived specimen is found to stop increasing at the stroke of about $0.8 \mathrm{~mm}$, indicating that the punch has penetrated through the foil. For the annealed specimens, the variations of drawing force with stroke can be divided into four stages, i.e., stages 1, 2, 3 and 4, as indicated in Figure 4 . In stage 1 , the punch starts to contact with the blank to induce slight and fluctuated contacting force until the stroke increases to $0.13 \mathrm{~mm}$, beyond which the MDD process enters stage 2 . In stage 2 , the drawing force has a rather slow increasing rate because at this stage the resistance of bending dominates the drawing force [29]. When the stroke is increased to around $0.35 \mathrm{~mm}$, the drawing force shows a rapid increase until reaching a peak value (stage 3). Finally, the drawing force decreases 
to a non-zero value at the end of the MDD process (stage 4). Beginning from stage 3, permanent deformation of the blank (ASS 304 foil) starts, which causes increased drawing force due to strain hardening with the deformation goes on, and simultaneously friction force increases with the increase of contact force between the blank and the die [30]. As the drawn cups undergo springback and the stored strain energy in the drawn cups releases after MDD [16], the drawing force is therefore non-zero due to the counterforce from blank applied to the punch, even though the punch has stopped moving down at the end of the MDD process.

Figure 5 shows the dependence of peak drawing force on annealing temperature for the specimens A700, A850, A900, A950, A1000 and A1100. It can be seen that the peak drawing force first drops sharply, and then becomes more slowly when the temperature is increased from $700{ }^{\circ} \mathrm{C}$ to $900{ }^{\circ} \mathrm{C}$. In the temperature range of $900{ }^{\circ} \mathrm{C}-950{ }^{\circ} \mathrm{C}$, only a slight drop of peak drawing force is found. When the temperature is over $950{ }^{\circ} \mathrm{C}$, the peak drawing force drops slowly again with the further increase of temperature.

The peak drawing force reflects the strength of the foils which is closely related to the microstructural characteristics. Figure 6 presents the typical tensile curves of the as-received, A850, A900, A950, A1000 and A1100 specimens, respectively. The tensile curves of the as-received specimens are found to exhibit rather low fracture stress and fracture strain, as shown in Figure 6a, indicating the specimens' very poor ductility. This is consistent with the result shown in Figure 4 that the stroke of the as-received specimen stops to increase at the early stage of MDD. Annealing treatment promotes the occurrence of recrystallization, by which the strength and the

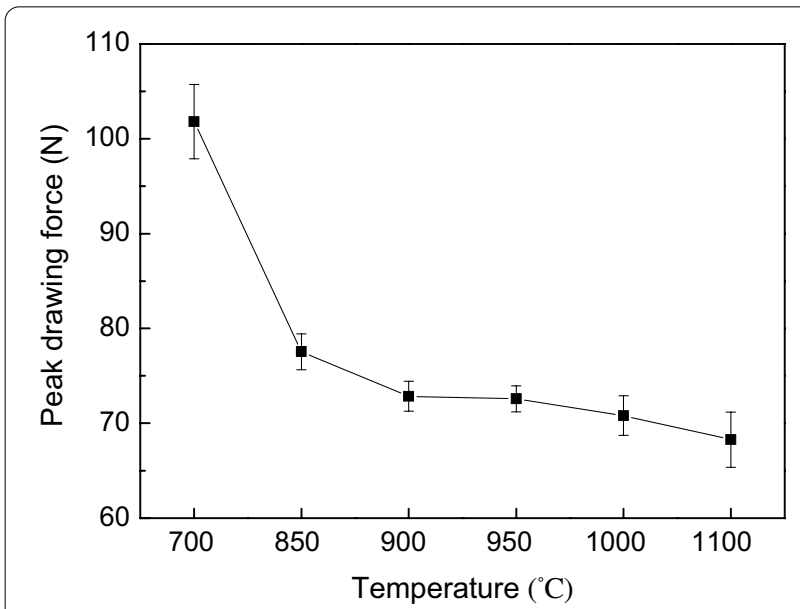

Figure 5 Dependence of peak drawing force on annealing temperature strain to fracture of the as-received specimen can be improved. With the increase of temperature, recrystallization becomes easier to occur, and the deformed grains are gradually replaced by a new set of defect-free grains that nucleate and grow until the original grains have been entirely consumed. During this process, the stored energy associated with various lattice defects created by the deformation will be released with the progress of recrystallization [24], which leads to reduction of the strength of annealed foils [31, 32], as shown in Figure 6b, c and $\mathrm{d}$, thereby the reduction of peak drawing force. When the temperature is over $950{ }^{\circ} \mathrm{C}$, the grain size increases significantly with a further increase of temperature (Figure 3). As a result, the grain boundary strengthening will decrease with the coarsening of grains. When the thickness of a specimen is kept a constant, the volume fraction of surface grains will increase with an increase in grain size. During deformation, the grains located on the surface show less constrains and their strength is lower as compared to that of the inner grains, because it is easy for the moving dislocations to pile up at grain boundaries, but unable to pile up in the surface grains during deformation [33]. Therefore, the peak drawing force will be reduced due to the reduction of foil's strength (Figure $6 e$ and $f$ ) with the increase of grain size $[1,34]$.

\subsection{Quality Evaluation of Drawn Cups}

The as-received ASS 304 foil is found to be unable to form a cup by MDD, with the process always ending with fractures of the drawn cups. Figure 7 shows an example of a fractured cup after MDD with the as-received ASS 304 foil. The result indicates that the as-received foil has rather poor formability, and appropriate heat treatment is therefore needed for successfully forming micro cups using MDD.

Figure 8 shows the top views of the drawn cups with annealed specimens. It can be seen that serious wrinkling occurs on the drawn cup with specimen annealed at $700{ }^{\circ} \mathrm{C}$ (Figure 8a), indicating the cup's poor quality. The wrinkling problem shows a decreasing trend with the increase of annealing temperature up to $900{ }^{\circ} \mathrm{C}$ (Figure 8b and c). The drawn cup with specimen annealed at $950{ }^{\circ} \mathrm{C}$ (Figure 8d) is found to exhibit a similar appearance as that annealed at $900{ }^{\circ} \mathrm{C}$ (Figure 8c), with both containing very few number of wrinkles. With a further increase of annealing temperature from $950{ }^{\circ} \mathrm{C}$ to $1000{ }^{\circ} \mathrm{C}$ and even $1100{ }^{\circ} \mathrm{C}$, the number of wrinkles increases gradually (Figure $8 \mathrm{e}$ and $\mathrm{f}$ ).

Figure 9 shows the height profiles of the drawn cups measured by laser scanning microscope, which correspond to the top views respectively shown in Figure 8. It should be noted that the directions of the images shown in Figure 9 may not exactly overlap with those shown 


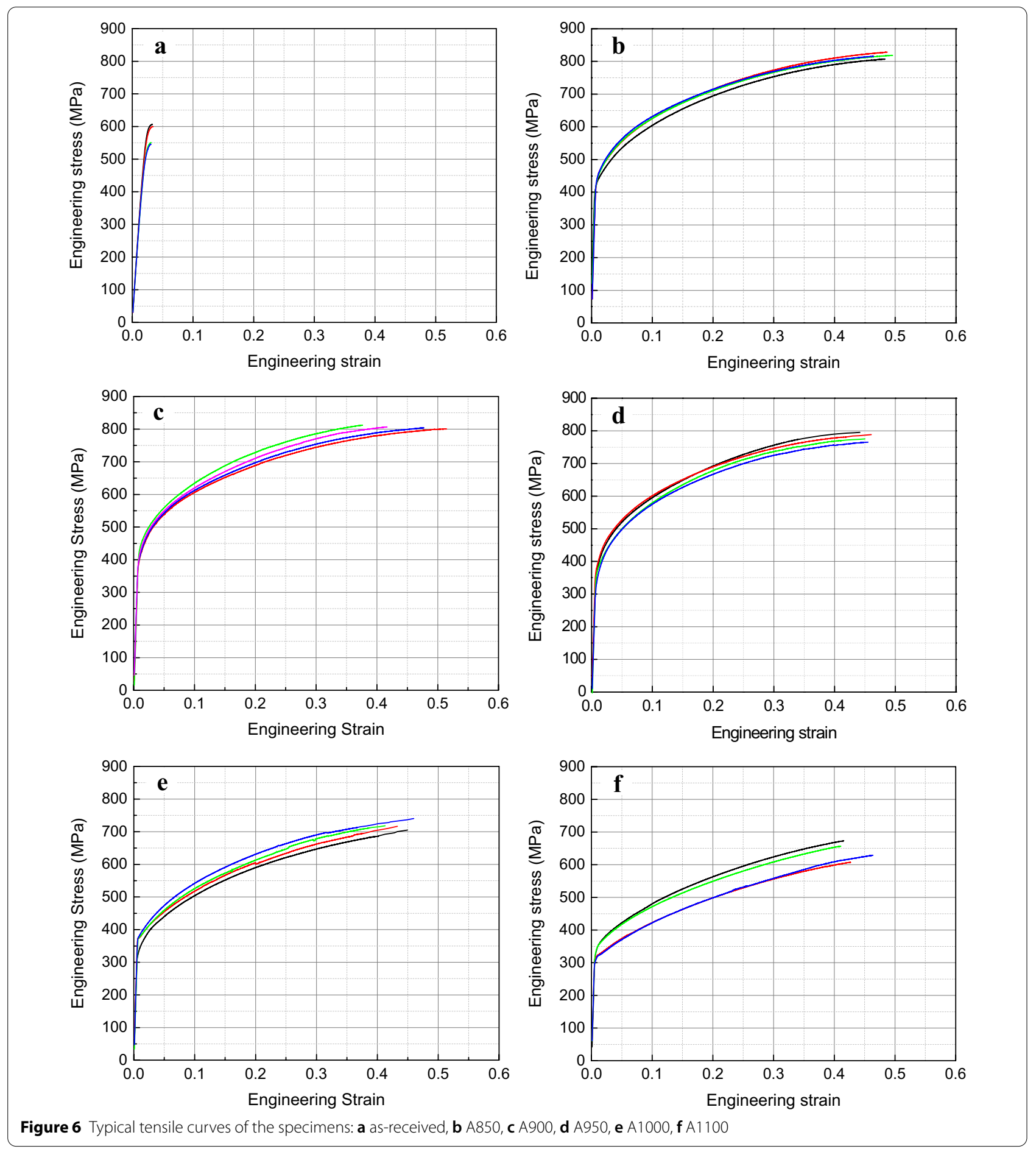

in Figure 8 as the images in both figures were respectively taken using different facilities. The drawn cups are colored according to their height information, and the cups' top-view profiles can be easily distinguished based on the variations of colors. For the specimen A700 (Figure 9a), the distribution of height profile on the mouth and along the direction from the edge to the central is quite non-uniform, and the mouth is not symmetrically circular. This is in consistence with the observation in Figure $8 \mathrm{a}$ that the quality of the drawn cup with specimen A700 is poor due to serious wrinkling. The distribution of height profile and the symmetry of the drawn 


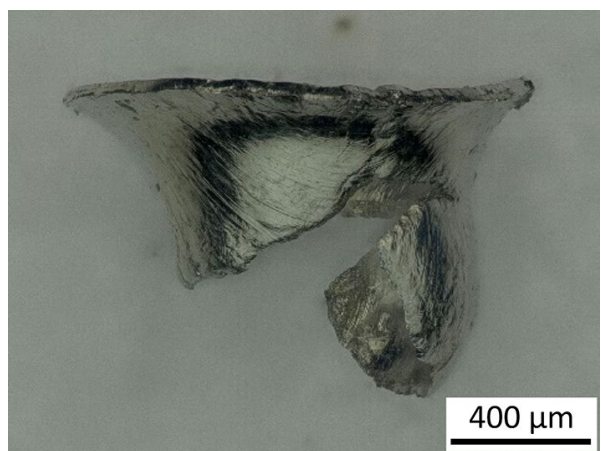

Figure 7 Side view of fractured cup after MDD with the as-received ASS 304 foil

cups become increasingly uniform with the increase of annealing temperature from $700{ }^{\circ} \mathrm{C}$ to $850{ }^{\circ} \mathrm{C}$, as shown in Figure 9b. The height profiles of the drawn cups with specimens A900 and A950 exhibit a similar characteristic, i.e. both circular cups, which contain very few defects along the cups' mouths, are with uniformly distributed height profile, symmetry and mouth thickness, as shown in Figure 9c and d. However, such a situation becomes worse due to the increased number of wrinkles with a further increase of annealing temperature (Figure 9e and f). Therefore, the drawn cups with specimens A900 and A950 are of high quality comparing to those with specimens A700, A850, A1000 and A1100 based on Figures 8 and 9 .

Figure 10 shows the side views of the drawn cups with annealed specimens. It is clear that the drawn cups with specimens A700 (Figure 10a), A850 (Figure 10b), A1000 (Figure 10e) and A1100 (Figure 10f) are all with wrinkling traces at the cups' edges, while wrinkles are hardly seen on the surfaces of the cups with specimens A900 (Figure 10c) and A950 (Figure 10d). Based on Figures 8, 9 and 10 , annealing temperatures of $900{ }^{\circ} \mathrm{C}$ and $950{ }^{\circ} \mathrm{C}$ are therefore the optimal for ASS 304 foils with the purpose of forming drawn cups with the fewest wrinkles using MDD.

Wrinkling is frequently encountered in deep drawing operations. Wrinkling is not recoverable after deep drawing, and has been regarded as a major obstacle in forming high quality drawn parts. In MDD, wrinkling has much more significant effect on the quality of drawn parts due to the microscale nature and the strict dimensional and tolerance requirements of the drawn parts comparing to those drawn by conventional deep drawing. In deep drawing, wrinkling is a negative consequence of shape change from a flat circular blank to a cylindrical cup, especially at the edge of the drawn part. In a deep drawing operation, an initially flat circular blank is drawn over a die by a cylindrical punch. The annular part of the blank is subjected to a radial tensile stress $\sigma_{\mathrm{t}}$, while compressive stress $\sigma_{\mathrm{c}}$ is generated in the circumferential direction during drawing, as shown in Figure 11a. When the
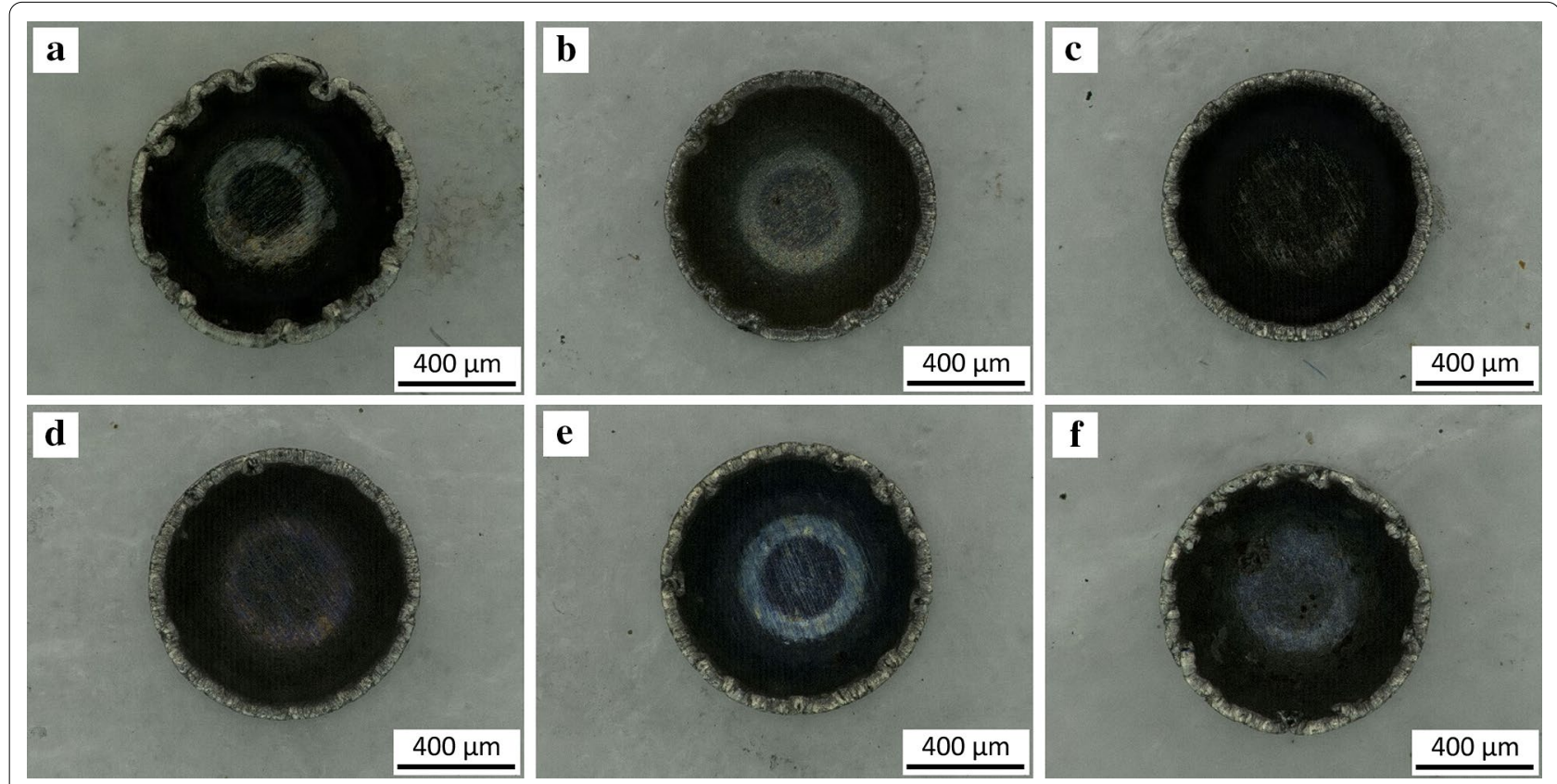

Figure 8 Top views of the drawn cups with annealed specimens: a A700, b A850, c A900, d A950, e A1000, f A1100 

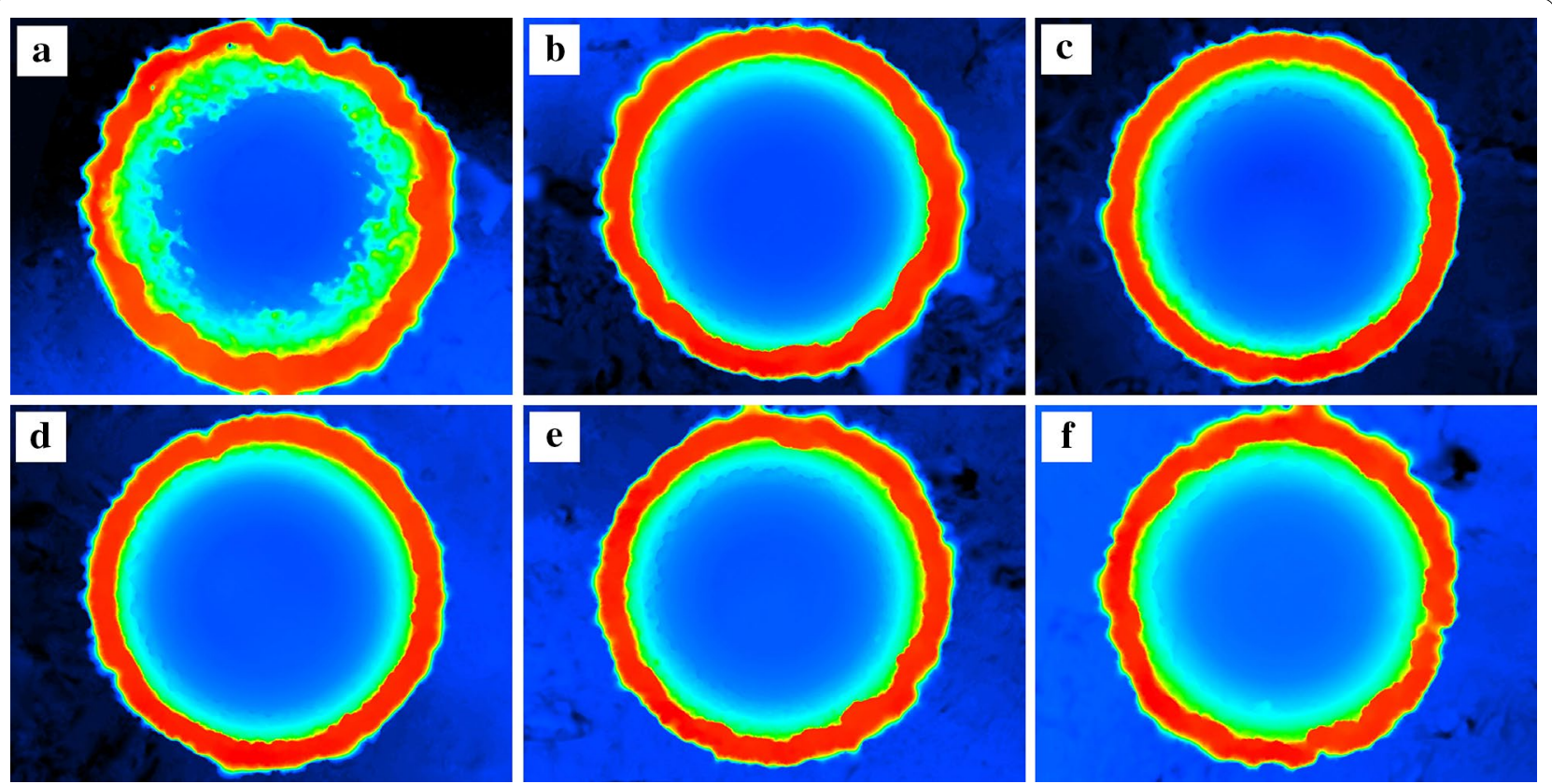

Figure 9 Height profiles of the drawn cups measured by laser microscope with annealed specimens: a A700, b A850, c A900, d A950, e A1000, f A1100
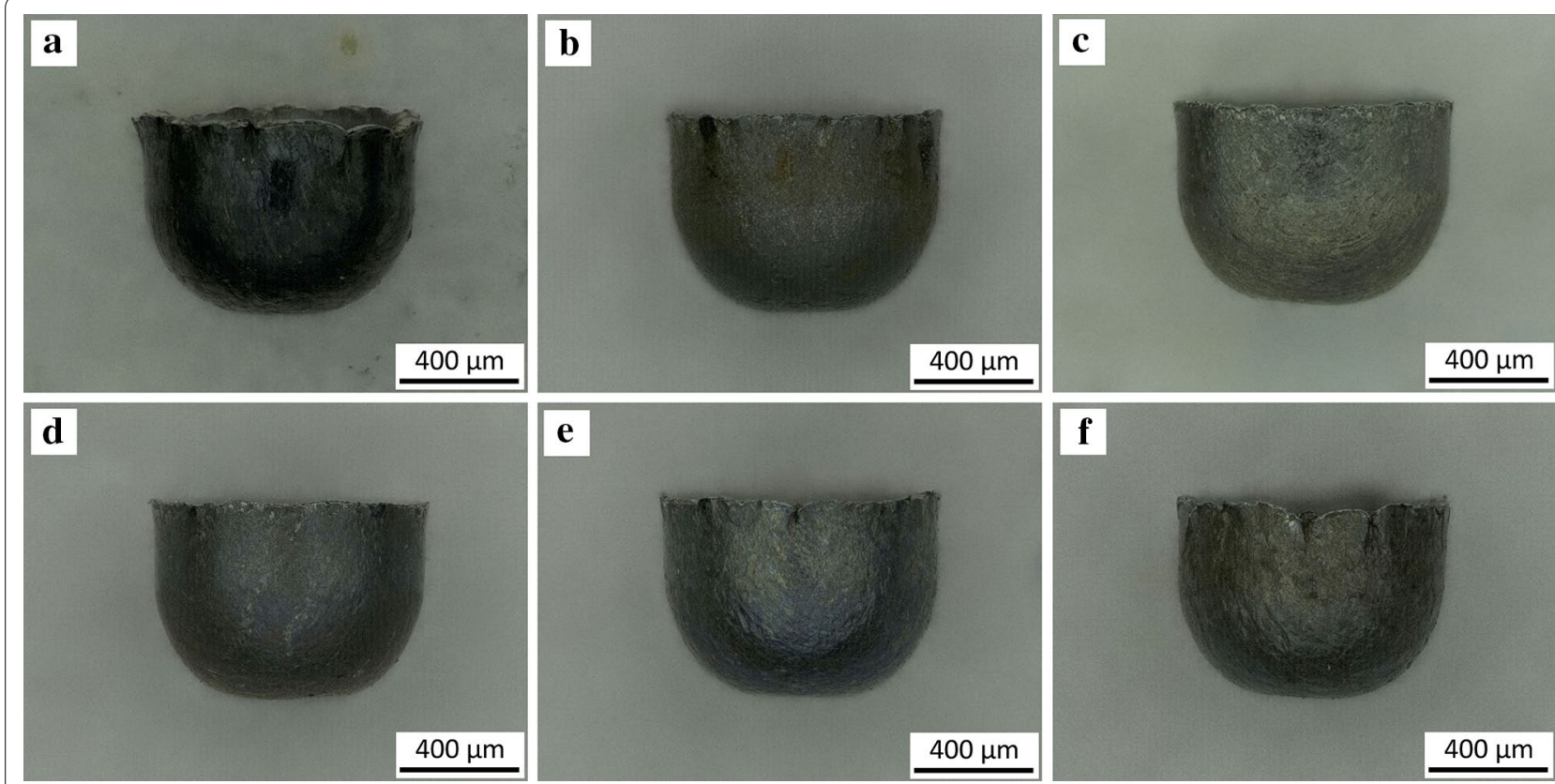

Figure 10 Side views of the drawn cups with annealed specimens: a A700, b A850, c A900, d A950, e A1000, f A1100

compressive stress $\sigma_{\mathrm{c}}$ reaches a critical point of instability, elastoplastic wave-shaped wrinkling of the blank will be generated, as schematically illustrated in Figure 11b. The onset of wrinkling in deep drawing is governed by a number of factors, including the geometry of tooling, blank holder stiffness, specifications of the blank, drawing procedure and material properties [35]. Wrinkling can be limited if a proper blank holding force is applied 

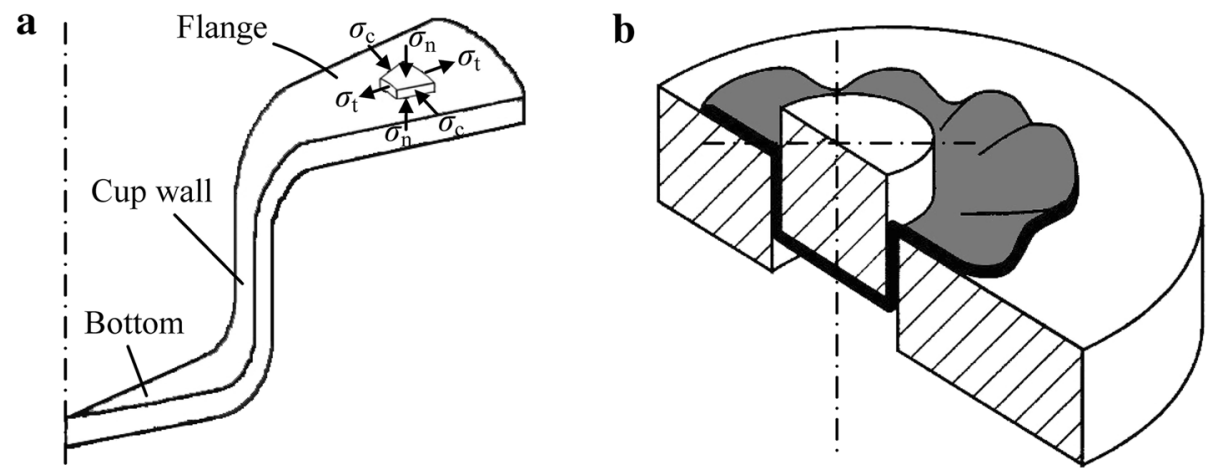

Figure 11 Schematic illustration of wrinkling generation in deep drawing: a stress conditions in flange, $\mathbf{b}$ wrinkling occurred in flange

in deep drawing, which has been studied theoretically, numerically and experimentally by a large number of researchers [36-38]. In general, unsupported regions of the blank that are subjected to high compressive circumferential stress are susceptible to wrinkling [39].

In the current work, only the microstructural characteristics of the blanks are variable. As recrystallization has not obviously occurred at $700{ }^{\circ} \mathrm{C}$, the elongated grain structure will induce inhomogeneous deformation of the specimen A700 during MDD. As a result, the distribution of the compressive stress $\sigma_{\mathrm{c}}$ in the circumferential direction becomes inhomogeneous, causing easy occurrence of localized deformation till wrinkling when the compressive stress reaches a critical value. With the increase of annealing temperature, recrystallization takes place easily, and the elongated grains are gradually broken up and replaced with recrystallized grains. Through such a process, the deformation of the recrystallized specimens will become increasingly homogeneous, contributing to the suppression of wrinkling due to the infrequently occurred local inhomogeneous deformation during MDD. Therefore, the degree of wrinkling exhibits a decreasing trend with the increase of annealing temperature from $700{ }^{\circ} \mathrm{C}$ to $900{ }^{\circ} \mathrm{C}$. The observations of the wrinkling occurred on the drawn cups with specimens A900 and A950 indicate that both specimens exhibit a similar deformation characteristic during MDD. The size of the recrystallized grains at $900{ }^{\circ} \mathrm{C}$ is finer than those at $950{ }^{\circ} \mathrm{C}$, but deformed characteristic is still observable in the specimen A900. Even though the specimen A950 is fully recrystallized, the grains are non-uniform in size due to abnormal growth of a number of recrystallized grains during annealing at $950{ }^{\circ} \mathrm{C}$. As a result, the specimens A900 and A950 exhibit a similar wrinkling behavior due to the balanced microstructural effects of both specimens.

When the annealing temperature is further increased from $950{ }^{\circ} \mathrm{C}$ to $1100{ }^{\circ} \mathrm{C}$, the average grain size is remarkably increased from 12 to $46 \mu \mathrm{m}$. As the thickness of all the specimens is the same, the number of grains in the specimens' thickness direction will be reduced with the increase of grain size. When a specimen comprises of only a few grains in the thickness direction, each grain will play a significant role in the specimen's deformation behavior. As a result, inhomogeneous and localized deformation can be easily caused because the characteristic of an individual grain will dominate the material behavior during MDD [1]. Consequently, it becomes easier for a coarse-grained specimen to generate wrinkles during MDD because the critical compressive stress value for wrinkling can be easily reached due to inhomogeneous and localized deformation, as compared to the specimen with finer grains. Therefore, wrinkling problem becomes increasingly worse with the coarsening of grains in the annealing temperature range of $950{ }^{\circ} \mathrm{C}-1100{ }^{\circ} \mathrm{C}$ (Figure $8 \mathrm{~d}-\mathrm{f}$ ).

\section{Conclusions}

The effects of microstructural characteristics on the formability of ASS 304 foils and the quality of drawn cups were investigated and discussed, and the optimal annealing temperatures for forming high quality drawn cups were proposed. The major conclusions derived from the present work are as follows:

1) Recrystallization of ASS 304 takes place easily with the increase of annealing temperature, but the microstructure cannot be fully recrystallized when the annealing temperature is lower than $950{ }^{\circ} \mathrm{C}$. The average grain sizes are $12 \mu \mathrm{m}, 20 \mu \mathrm{m}$ and $46 \mu \mathrm{m}$ for the specimens annealed at $950{ }^{\circ} \mathrm{C}, 1000{ }^{\circ} \mathrm{C}$ and $1100{ }^{\circ} \mathrm{C}$, respectively.

2) The drawing force of the annealed ASS 304 foils goes through four stages with stroke during MDD. The peak drawing force drops greatly when the annealing temperature is increased from $700{ }^{\circ} \mathrm{C}$ to $900{ }^{\circ} \mathrm{C}$, 
then decreases slightly in the temperature range of $900{ }^{\circ} \mathrm{C}-950{ }^{\circ} \mathrm{C}$, and finally descends slowly when the temperature is over $950{ }^{\circ} \mathrm{C}$, which are closely related to the microstructural characteristics of the annealed ASS 304 foils.

3) The as-received ASS 304 foil is unable to form a cup by MDD due to its poor formability. Significant wrinkling occurs on the drawn cup with specimen annealed at $700{ }^{\circ} \mathrm{C}$. The drawn cups with specimens annealed at $900{ }^{\circ} \mathrm{C}$ and $950{ }^{\circ} \mathrm{C}$ contain very few wrinkles, but the number of wrinkles increases gradually with a further increase of annealing temperature from $950{ }^{\circ} \mathrm{C}$ to $1100{ }^{\circ} \mathrm{C}$.

4) The height profile distribution and symmetry of the drawn cups become increasingly uniform with the increase of annealing temperature from $700{ }^{\circ} \mathrm{C}$ to $900{ }^{\circ} \mathrm{C}$, but become worse when the annealing temperature is over $950{ }^{\circ} \mathrm{C}$ due to the occurrence of wrinkling. The drawn cups with specimens annealed at $900{ }^{\circ} \mathrm{C}$ and $950{ }^{\circ} \mathrm{C}$ are characterized with uniformly distributed height profile, symmetry and mouth thickness.

5) Appropriate selection of annealing temperature is very important with the purpose of reducing the generation of wrinkling, and therefore improving the quality of drawn cups. The optimal annealing temperatures obtained in the present work are $900{ }^{\circ} \mathrm{C}$ and $950{ }^{\circ} \mathrm{C}$ for ASS 304 foils for forming drawn cups with the fewest wrinkles by MDD.

\section{Acknowledgements}

Not applicable.

\section{Authors' contributions}

$J Z$ conceived the research and wrote the manuscript; JZ, FJ and ZL conducted experiments; TW, CZ, QH and ZJ revised the manuscript. All authors read and approved the final manuscript.

\section{Authors' information \\ Jingwei Zhao, born in 1980, is currently a professor and a PhD supervisor at College of Mechanical and Vehicle Engineering and TYUT-UOW Joint Research Center, Taiyuan University of Technology, China, and Engineering Research Center of Advanced Metal Composites Forming Technology and Equipment, Ministry of Education, China. His research interests include microforming of metallic materials, and rolling technology and equipment.}

Tao Wang, born in 1985, is currently an associate professor at College of Mechanical and Vehicle Engineering and TYUT-UOW Joint Research Center, Taiyuan University of Technology, China, and Engineering Research Center of Advanced Metal Composites Forming Technology and Equipment, Ministry of Education, China. His research interests include metal forming and processing, and rolling technology and equipment.

Fanghui Jia, born in 1989, is currently a PhD candidate at School of Mechanical, Materials, Mechatronic and Biomedical Engineering and TYUT-UOW Joint Research Center, University of Wollongong, Australia. His research interests include micro forming of metallic materials, and micro rolling technology.

Zhou Li, born in 1987, is currently a PhD candidate at School of Mechanical, Materials, Mechatronic and Biomedical Engineering and TYUT-UOW Joint
Research Center, University of Wollongong, Australia. His research interests include metal forming, and properties evaluation of metal composites.

Cunlong Zhou, born in 1965, is currently a professor and a PhD supervisor at Shanxi Provincial Key Laboratory on Metallurgical Device Design and Theory, Taiyuan University of Science and Technology, China. His research interests include metal forming, rolling technology, and shape control in metal rolling.

Qingxue Huang, born in 1961, is currently an Academician of Chinese Academy of Engineering, a professor and a PhD supervisor at College of Mechanical and Vehicle Engineering and TYUT-UOW Joint Research Center, Taiyuan University of Technology, China, and Engineering Research Center of Advanced Metal Composites Forming Technology and Equipment, Ministry of Education, China. His research interests include rolling theory, metal composites forming, and intelligent robot and equipment.

Zhengyi Jiang, born in 1962, is currently a professor and a PhD supervisor at School of Mechanical, Materials, Mechatronic and Biomedical Engineering and TYUT-UOW Joint Research Center, Australia, and Shanxi Provincial Key Laboratory on Metallurgical Device Design and Theory, Taiyuan University of Science and Technology, China. His research interests include micromanufacturing of metallic materials, rolling theory and technology, and quality control in metal forming.

\section{Funding}

Supported by National Natural Science Foundation of China (Grant Nos. 51975398, 51974196), and Research Project Supported by Shanxi Scholarship Council of China (Grant No. 2020-037).

\section{Declaration}

\section{Competing interests}

The authors declare that they have no competing interest.

\section{Author Details}

${ }^{1}$ College of Mechanical and Vehicle Engineering, Taiyuan University of Technology, Taiyuan 030024, China. ${ }^{2}$ Engineering Research Center of Advanced Metal Composites Forming Technology and Equipment, Ministry of Education, Taiyuan 030024, China. ${ }^{3}$ TYUT-UOW Joint Research Center, Taiyuan University of Technology, Taiyuan 030024, China. ${ }^{4}$ TYUT-UOW Joint Research Center, University of Wollongong, Wollongong, NSW 2522, Australia. ${ }^{5}$ School of Mechanical, Materials, Mechatronic and Biomedical Engineering, University of Wollongong, Wollongong, NSW 2522, Australia. ${ }^{6}$ Shanxi Provincial Key Laboratory on Metallurgical Device Design and Theory, Taiyuan University of Science and Technology, Taiyuan 030024, China.

Received: 7 March 2020 Revised: 20 December 2020 Accepted: 16 March 2021

Published online: 19 April 2021

\section{References}

[1] J Zhao, M Huo, X Ma, et al. Study on edge cracking of copper foils in micro rolling. Materials Science and Engineering A, 2019, 747: 53-62.

[2] C J Wang, L D Cheng, Y Liu, et al. Research on micro-deep drawing process of concial part with ultra-thin copper foil using multi-layered DLC film-coated die. International Journal Advanced Manufacturing Technology, 2019, 100: 569-575.

[3] Z Jiang, J Zhao, H Lu, et al. Influences of temperature and grain size on the material deformability in microforming process. International Journal Material Forming, 2017, 10: 753-764.

[4] MW Fu, J L Wang, A M Korsunsky. A review of geometrical and microstructural size effects in micro-scale deformation processing of metallic alloy components. International Journal of Machine Tools and Manufacture, 2016, 109: 94-125.

[5] F Gong, Z Yang, Q Chen, et al. Influences of lubrication conditions and blank holder force on micro deep drawing of C1100 micro conical-cylindrical cup. Precision Engineering, 2015, 42: 224-230.

[6] A Molotnikov, R Lapovok, C F Gu, et al. Size effects in micro cup drawing. Materials Science and Engineering A, 2012, 550: 312-319. 
[7] M W Fu, B Yang, W L Chan. Experimental and simulation studies of micro blanking and deep drawing compound process using copper sheet. Journal of Materials Processing Technology, 2013, 213: 101-110.

[8] J Zhao, Z Jiang. Thermomechanical processing of advanced high strength steels. Progress in Materials Science, 2018, 94: 174-242.

[9] C H Chen, J T Gau, R S Lee. An experimental and analytical study on the limit drawing ration of stainless steel 304 foils for microsheet forming. Materials and Manufacturing Processes, 2009, 24: 1256-1265.

[10] X Ma, J Zhao, W Du, et al. Study on micro hydro-mechanical deep drawing using finite element method. MATEC Web of Conferences, 2016, 80: 02009.

[11] Y M Huang, Y SWu, JY Huang. The influence of ultrasonic vibrationassisted micro-deep drawing process. International Journal of Advanced Manufacturing Technology, 2014, 71: 1455-1461.

[12] H Sato, K Manabe, K Ito, et al. Development of servo-type micro-hydromechanical deep-drawing apparatus and micro deep-drawing experiments of circular cups. Journal of Materials Processing Technology, 2015, 224: 233-239.

[13] H Sato, K I Manabe, D Wei, et al. Tribological behavior in micro-sheet hydroforming. Tribology International, 2016, 97: 302-312

[14] L Luo, D Wei, X Wang, et al. Effects of hydraulic pressure on wrinkling and earing in micro hydro deep drawing of SUS304 circular cups. International Journal of Advanced Manufacturing Technology, 2017, 90: 189-197.

[15] L Luo, Z Jiang, D Wei, et al. Micro-hydromechanical deep drawing of metal cups with hydraulic pressure effects. Frontiers of Mechanical Engineering, 2018, 13: 66-73.

[16] L Luo, Z Jiang, D Wei, et al. An experimental and numerical study of micro deep drawing of SUS304 circular cups. Manufacturing Review, 2015, 2: 27.

[17] L Luo, Z Jiang, D Wei, et al. Effects of surface roughness on micro deep drawing of circular cups with consideration of size effects. Finite Elements in Analysis and Design, 2016, 111: 46-55.

[18] L Luo, Z Jiang, D Wei. Influences of micro-friction on surface finish in micro deep drawing of SUS304 cups. Wear, 2017, 374-375: 36-45.

[19] C C Chang, H S Chen. Effect of grain size on micro deep drawing of SUS304 stainless steel square cup. Key Engineering Materials, 2015, 661: 77-82.

[20] R S Lee, C H Chen, JT Gau. Effect of thickness to grain size ratio on drawability for micro deep drawing of AISI 304 stainless steel. The 9th International Conference on Technology of Plasticity, Gyeongju, South Korea, 7-11 September 2008.

[21] J T Gau, S Teegala, K M Huang, et al. Using micro deep drawing with ironing stages to form stainless steel 304 micro cups. Journal of Manufacturing Processes, 2013, 15: 298-305.

[22] ASTM E8/E8M-11. Standard Test Methods for Tension Testing of Metallic Materials. ASTM International, West Conshohocken, PA, 2011.

[23] Y S Sato, TW Nelson, C J Sterling. Recrystallization in type 304L stainless steel during friction stirring. Acta Materialia, 2005, 53: 637-645.
[24] A F Padilha, R L Plaut, P R Rios. Annealing of cold-worked austenitic stainless steels. ISIJ International, 2003, 43: 135-143.

[25] L F M Martins, R L Plaut, A F Padilha. Effect of carbon on the cold-worked state and annealing behavior of two $18 \mathrm{wt} \% \mathrm{Cr}-8 \mathrm{wt} \% \mathrm{Ni}$ austenitic stainless steels. ISIJ International, 1998, 38: 572-579.

[26] G S Sun, LX Du, J Hu, et al. Ultrahigh strength nano/ultrafine-grained 304 stainless steel through three-stage cold rolling and annealing treatment. Materials Characterization, 2015, 110: 228-235.

[27] Z J Zheng, J W Liu, Y Gao. Achieving high strength and high ductility in 304 stainless steel through bi-modal microstructure prepared by postECAP annealing. Materials Science and Engineering A, 2007, 680: 426-432.

[28] ASTM E112-13. Standard Test Methods for Determining Average Grain Size. ASTM International, West Conshohocken, PA, 2013.

[29] F Jia, J Zhao, L Luo, et al. Experimental and numerical study on micro deep drawing with aluminium-copper composite material. Procedia Engineering, 2017, 207: 1051-1056.

[30] Z Jiang, J Zhao, H Xie. Microforming technology: Theory, simulation, and practice. Netherlands: Elsevier, 2017.

[31] Y Xiong, THe, H Li, et al. Annealing effects on microstructure and mechanical properties of cryorolled Fe-25Cr-20Ni steel. Materials Science and Engineering A, 2017, 703: 68-75.

[32] J T Shi, L G Hou, J R Zuo, et al. Effect of cryogenic rolling and annealing on the microstructure evolution and mechanical properties of 304 stainless steel. International Journal of Minerals, Metallurgy and Materials, 2017, 24: 638-645.

[33] S Miyazaki, K Shibata, H Fujita. Effect of specimen thickness on mechanical properties of polycrystalline aggregates with various grain sizes. Acta Metallurgica, 1979, 27: 855-862.

[34] T A Kals, R Eckstein. Miniaturization in sheet metal working. Journal of Materials Processing Technology, 2000, 103: 95-101.

[35] E Chu, Y Xu. An elastoplastic analysis of flange wrinkling in deep drawing process. International Journal of Mechanical Sciences, 2001, 43: 1421-1440.

[36] M R Morovvati, B Mollaei-Dariani, M H Asadian-Ardakani. A theoretical, numerical, and experimental investigation of plastic wrinkling of circular two-layer sheet metal in the deep drawing. Journal of Materials Processing Technology, 2010, 210: 1738-1747.

[37] R K Saxena, P M Dixit. Prediction of flange wrinkling in deep drawing process using bifurcation criterion. Journal of Manufacturing Processes, 2010, 12: 19-29

[38] M Ahmetoglu, TR Broek, G Kinzel, et al. Control of blank holder force to eliminate wrinkling and fracture in deep-drawing rectangular parts. CIRP Annals, 1995, 44: 247-250.

[39] J Hematian. Finite element modeling of wrinkling during deep drawing of pressure vessel end closures (PVECS). Queen's University, 2000.

\section{Submit your manuscript to a SpringerOpen ${ }^{\circ}$ journal and benefit from:}

- Convenient online submission

- Rigorous peer review

- Open access: articles freely available online

- High visibility within the field

- Retaining the copyright to your article

Submit your next manuscript at springeropen.com 